\title{
Pharmacokinetic Drug Interaction between Carvedilol and Ticlopidine in Rats
}

\author{
Jun-Shik $\mathrm{CHOI}^{1}$, and Dong-Hyun $\mathrm{CHOI}^{2, *}$ \\ ${ }^{1}$ College of Pharmacy, ${ }^{2}$ College of Medicine, Chosun University, Gwangju 501-759, Republic of Korea
}

(Received May 31, 2010; Revised July 6, 2010; Accepted July 7, 2010)

\begin{abstract}
This study was designed to investigate the effects of ticlopidine on the pharmacokinetics of carvedilol after oral or intravenous administration of carvedilol in rats. Carvedilol was administered orally (3 $\mathrm{mg} / \mathrm{kg}$ ) or intravenously $(1 \mathrm{mg} / \mathrm{kg}$ ) without or with oral administration of ticlopidine $(4,12 \mathrm{mg} / \mathrm{kg})$ to rats. The effects of ticlopidine on P-glycoprotein (P-gp) and cytochrome P450 (CYP) 2C9 activity were also evaluated. Ticlopidine inhibited CYP2C9 activity in a concentration-dependent manner with $50 \%$ inhibition concentration $\left(\mathrm{IC}_{50}\right)$ of $25.2 \mu \mathrm{M}$. In addition, ticlopidine could not significantly enhance the cellular accumulation of rhodamine 123 in MCF-7/ADR cells overexpressing P-gp. Compared with the control group (given carvedilol alone), the area under the plasma concentration-time curve (AUC) was significantly $(12 \mathrm{mg} / \mathrm{kg}, p<0.05)$ increased by $14-41 \%$, and the peak concentration $\left(C_{\max }\right)$ was significantly $(12 \mathrm{mg} / \mathrm{kg}, p<0.05)$ increased by $10.7-73.3 \%$ in the presence of ticlopidine after oral administration of carvedilol. Consequently, the relative bioavailability (R.B.) of carvedilol was increased by $1.14-$ to 1.41 -fold and the absolute bioavailability (A.B.) of carvedilol in the presence of ticlopidine was increased by $36.2-38.5 \%$. Compared to the i.v. control, ticlopidine could not significantly change the pharmacokinetic parameters of i.v. administered carvedilol. The enhanced oral bioavailability of carvedilol may result from inhibition of CYP2C9-mediated metabolism rather than P-gpmediated efflux of carvedilol in the intestinal and/or in liver and renal eliminatin of carvedilol by ticlopidine.
\end{abstract}

Keywords: Carvedilol, Ticlopidine, CYP2C9, P-glycoprotein, Pharmacokinetics, Bioavailability

\section{INTRODUCTION}

Ticlopidine is extensively metabolized in the liver and is a potent inhibitor of platelet aggregation caused by adenosine diphosphate (ADP), whereas its ability to inhibit aggregation induced by collagen, thrombin, arachidonic acid, adrenaline, and platelet-activating factor varies (Saltiel and Ward, 1987). It has been tried in a variety of platelet-dependent disease states (Gent et al., 1989; Hass et al., 1989; Janzon et al., 1990). Indeed, several recent reviews recommend ticlopidine as a valuable alternative when patients cannot tolerate aspirin (Verhaeghe, 1991; Ito et al., 1992; Solomon and Hart, 1994; Buur et al., 1997; Haynes et al., 1998; Ko et al., 2000).

Ticlopidine is an antiplatelet drug reported to cause significant inhibition of several drugs metabolized by the hepatic cytochrome P-450 enzyme system, including theo-

${ }^{*}$ Corresponding author

Tel: +82-62-220-3773 Fax: +82-62-222-3858

E-mail: dhchoi@chosun.ac.kr phylline and antipyrine. For example, ticlopidine co-medication results in a significant increase in mean warfarin concentrations (Gidal et al., 1995). There is also report that the oral bioavailability of ticlopidine administered with meal was increased by $20 \%$ and the absorption of ticlopidine administered with antacid was approximately $20 \%$ lower than those under fasting conditions (Shah et al., 1990). Furthermore, we evaluated the inhibition of CYP enzyme activity and $\mathrm{P}$-gp activity by ticlopidine using CYP inhibition assays and rhodamine- 123 retention assays in P-gp-overexpressing MCF-7/ADR cells.

Carvedilol is an arylethanolamine and has nonspecific $\beta$ - and $\alpha_{1}$-adrenergic blocking effects (Bristow et al., 1992). Carvedilol also reduces the release of endothelin and directly scavenges free radicals of oxygen (Feuerstein et al., 1997). It is used to treat systemic arterial hypertension (Cournot et al., 1992; Lund-Johansen et al., 1992) and congestive heart failure (DasGupta et al., 1991) and is purported to improve exercise capacity (Cleland et al., 1996; Hampton, 1996) and longevity in humans (Bristow et al., 
1996).

Carvedilol is well absorbed from the gastrointestinal tract, but is subject to considerable first-pass metabolism in the intestinal and/or liver (McTavish et al., 1993; Morgan et al., 1994). Carvedilol is more than $98 \%$ bound to plasma proteins. Carvedilol is metabolized by both oxidation and conjugation pathways in the liver into some metabolites (Neugebauer et al., 1987; Neugebauer and Neubert, 1991). The oxidation pathways are mainly catalyzed by CYP2C9 and CYP2D6 enzymes in human (McTavish and Neubert, 1993; Morgan, 1994; Oldham and Clarke, 1997), and then CYP2D6 is responsible for the formation of 4'-hydroxy carvedilol and 5'-hydroxy carvedilol, and both metabolites are excreted into urine (Neugebauer and Neubert, 1991). Carvedilol is also a substrate of P-gp (Bart and Neubert, 2005). Since carvedilol is a substrate of both CYP enzymes and P-gp, the modulation of CYP and P-gp activities may cause the significant changes in the pharmacokinetic profile of carvedilol.

Clinically carvedilol and ticlopidine can be prescribed for treatment of cardiovascular disease. However, pharmacokinetic interaction between ticlopidine and carvedilol has not been reported in vivo. Therefore, the present study aims to investigate the effect of ticlopidine on the bioavailability and pharmacokinetics of carvedilol after oral and intravenous administration in rats.

\section{MATERIALS AND METHODS}

\section{Chemicals and apparatus}

Carvedilol, ticlopidine and nimodipine [an internal standard for high-performance liquid chromatograph (HPLC) analysis for carvedilol] were purchased from Sigma-Aldrich Co. (St. Louis, MO, USA). HPLC grade acetonitrile was acquired from Merck Co. (Darmstadt, Germany). Other chemicals for this study were of reagent grade.

Apparatuses used in this study were a HPLC equipped with a Waters 1515 isocratic HPLC Pump, a Waters 717 plus autosampler and a Waters $^{\mathrm{TM}} 474$ scanning fluorescence detector (Waters Co., Milford, MA, USA), a HPLC column temperature controller (Phenomenex Inc., CA, USA), a Bransonic ${ }^{\circledR}$ Ultrasonic Cleaner (Branson Ultrasonic Co., Danbury, CT, USA), a vortex-mixer (Scientific Industries Co., NY, USA) and a high-speed micro centrifuge (Hitachi Co., Tokyo, Japan).

\section{Animal experiments}

Male Sprague-Dawley rats of 7-8 weeks of age (weighing 270-300 g) were purchased from Dae Han Laboratory Animal Research Co. (Choongbuk, Republic of Korea) and given free access to a commercial rat chow diet (No. 3227-1; Superfeed Co., Gangwon, Republic of Korea) and tap water ad libitum. The animals were housed (two rats per cage) in a clean room maintained at a temperature of $22 \pm$ $2^{\circ} \mathrm{C}$ and relative humidity of $50-60 \%$, with $12 \mathrm{~h}$ light and dark cycles. The rats were acclimated under these conditions for at least 1-week. All animal studies were performed in accordance with the "Guiding Principles in the Use of Animals in Toxicology" adopted by the Society of Toxicology (USA) and the Animal Care Committee of Chosun University (Gwangju, Republic of Korea) approved the protocol of this animal study. The rats were fasted for at least $24 \mathrm{~h}$ prior to beginning the experiments and had free access to tap water. Each animal was anaesthetized lightly with ether. The left femoral artery and vein were cannulated using polyethylene tubing (SP45, I.D. $0.58 \mathrm{~mm}$, O.D. $0.96 \mathrm{~mm}$; Natsume Seisakusho Co. LTD., Tokyo, Japan) for blood sampling and i.v. injection, respectively.

\section{Oral and intravenous administration of carvedilol}

The rats were divided into four groups ( $n=6$, each): an oral group ( $3 \mathrm{mg} / \mathrm{kg}$ of carvedilol dissolved in water; homogenized at $36^{\circ} \mathrm{C}$ for $30 \mathrm{~min} ; 3.0 \mathrm{ml} / \mathrm{kg}$ ) without (control) or with 4 or $12 \mathrm{mg} / \mathrm{kg}$ of oral ticlopidine, and an i.v. group (1 $\mathrm{mg} / \mathrm{kg}$ of carvedilol, dissolved in $0.9 \% \mathrm{NaCl}$ solution; homogenized at $36^{\circ} \mathrm{C}$ for $30 \mathrm{~min} ; 1.5 \mathrm{ml} / \mathrm{kg}$ ) without (control) or with 4 or $12 \mathrm{mg} / \mathrm{kg}$ of oral ticlopidine. Ticlopidine was orally administered 30 min prior to oral or intravenous administration of carvedilol. Oral carvedilol was administered through a feeding tube, and carvedilol for i.v. administration was injected through the femoral vein within 0.5 $\mathrm{min}$. A 0.4-ml blood sample was collected into heparinized tubes from the femoral artery at 0, 0.1, 0.25, 0.5, 1, 2, 4, 8, 12 and $24 \mathrm{~h}$ after intravenous infusion and at $0,0.25,0.5$, $1,2,4,8,12$ and $24 \mathrm{~h}$ after oral administration. The blood samples were centrifuged $(13,000 \mathrm{rpm}, 5 \mathrm{~min})$, and the plasma samples were stored at $-40^{\circ} \mathrm{C}$ until HPLC analysis of carvedilol. Rats were infused with approximately $1 \mathrm{ml}$ of whole blood collected from untreated rats via the femoral artery at $0.5,2$ and $8 \mathrm{~h}$ to replace the blood loss due to blood sampling.

\section{HPLC assay}

The plasma concentrations of carvedilol were determined by the HPLC assay method reported by Zarghi et al. (2007). Briefly, $50 \mu \mathrm{l}$ of dihydroerogostine $(20 \mu \mathrm{g} / \mathrm{ml}$ dissolved in methanol; an internal standard) and $0.5 \mu \mathrm{l}$ of acetonitrile were added to a $0.2 \mathrm{ml}$ aliquot of the plasma in a $2.0 \mathrm{ml}$ polypropylene microtube. The mixture was then stirred for $10 \mathrm{~min}$ and centrifuged (130,000 rpm, $10 \mathrm{~min})$. A 
$0.5 \mathrm{ml}$ aliquot of the organic layer was transferred to a clean test tube and evaporated under a gentle stream of nitrogen gas at $35^{\circ} \mathrm{C}$. The residue was reconstituted in a $150 \mu$ of the mobile phase and centrifuged (13,000 rpm, 5 min). The resulting mixture was then vigorously vortexmixed for $5 \mathrm{~min}$ and centrifuged at $13,000 \mathrm{rpm}$ for $5 \mathrm{~min}$. A $50-\mu l$ aliquot of the supernatant was injected into the HPLC system. Chromatographic separations were achieved using a Chromolith Performance (RP-18e, 100×4.6 mm) column from Merck (Darmstadt, Germany). The mobile phase consisted of $0.01 \mathrm{M}$ disodium hydrogen phosphate $(\mathrm{pH}$ 3.5 , adjusted with phosphoric acid)-acetonitrile (75.7:24.3, $\mathrm{v} / \mathrm{v})$. The flow rate of the mobile phase was maintained at $2.0 \mathrm{ml} / \mathrm{min}$. Chromatography was performed at of $25^{\circ} \mathrm{C}$, which was regulated by an HPLC column temperature controller. The fluorescence detector was operated at an excitation wavelength of $240 \mathrm{~nm}$ with an emission wavelength of $340 \mathrm{~nm}$. The retention times at a flow rate of 2 $\mathrm{ml} / \mathrm{min}$ were as follows: carvedilol at $8.076 \mathrm{~min}$ internal standard at $9.305 \mathrm{~min}$. The lower limit of quantification for carvedilol in rat plasma was $10 \mathrm{ng} / \mathrm{ml}$. The coefficient of the variation of carvedilol was less than $14.3 \%$.

\section{CYP 2C9 inhibition assay}

The assays of inhibition on human 2C9 enzyme activities were performed in a multiwell plate using CYP inhibition assay kit (GENTEST, Woburn, MA) as described previously (Crespi et al., 1997). Briefly, human CYP enzymes were obtained from baculovirus-infected insect cells. CYP substrates (7-MFC for CYP2C9) were incubated with or without test compounds in the enzyme/substrate contained buffer consisting of $1 \mathrm{pmol}$ of P450 enzyme and NADPH generating system (1.3 mM NADP, $3.54 \mathrm{mM}$ glucose 6-phosphate, $0.4 \mathrm{U} / \mathrm{ml}$ glucose 6-phosphate dehydrogenase and $3.3 \mathrm{mM} \mathrm{MgCl}_{2}$ ) in a potassium phosphate buffer ( $\mathrm{pH}$ 7.4). Reactions were terminated by adding stop solution after $45 \mathrm{~min}$ incubation. Metabolite concentrations were measured by spectrofluorometer (Molecular Device, Sunnyvale, CA) set at an excitation wavelength of $409 \mathrm{~nm}$ and an emission wavelength of $530 \mathrm{~nm}$. Positive control (1 $\mu \mathrm{M}$ ketoconazole for CYP2C9) was run on the same plate and produced $99 \%$ inhibition. All experiments were performed in duplicate, and results are expressed as the percent of inhibition.

\section{Rhodamine-123 retention assay}

MCF-7/ADR cells were seeded in 24-well plates. At $80 \%$ confluence, the cells were incubated in FBS-free DMEM for $18 \mathrm{~h}$. The culture medium was changed to Hanks' balanced salt solution and the cells were incubated at $37^{\circ} \mathrm{C}$ for $30 \mathrm{~min}$. After incubation of the cells with $20 \mathrm{mM}$ rhodamine-123 for $90 \mathrm{~min}$, the medium was completely removed. The cells were then washed three times with ice-cold phosphate buffer $(\mathrm{pH} 7.0)$ and lysed in lysis buffer. The rhodamine-123 fluorescence in the cell lysates was measured using excitation and emission wavelengths of 480 and 540 $\mathrm{nm}$, respectively. Fluorescence values were normalized to the total protein content of each sample and presented as the ratio to controls.

\section{Pharmacokinetic analysis}

The plasma concentration data were analyzed by the noncompartmental method using WinNonlin software version 4.1 (Pharsight Co., Mountain View, CA, USA). The elimination rate constant $\left(\mathrm{K}_{\mathrm{el}}\right)$ was calculated by log-linear regression of carvedilol concentration data during the elimination phase, and the terminal half-life $\left(t_{1 / 2}\right)$ was calculated by $0.693 / \mathrm{K}_{\mathrm{el}}$. The peak concentration $\left(\mathrm{C}_{\max }\right)$ and the time to reach peak concentration $\left(T_{\max }\right)$ of carvedilol in plasma were obtained by visual inspection of the data from the concentration-time curve. The area under the plasma concentration-time curve $\left(\mathrm{AUC}_{0-\mathrm{t}}\right)$ from time zero to the time of last measured concentration $\left(\mathrm{C}_{\text {last }}\right)$ was calculated by the linear trapezoidal rule. The $A \cup C$ zero to infinity $\left(\mathrm{AUC}_{0-\infty}\right)$ was obtained by the addition of $A \cup C_{0-t}$ and the extrapolated area determined by $\mathrm{C}_{\text {last }} / \mathrm{K}_{\mathrm{el}}$. Total body clearance (CL/F) was calculated by Dose/AUC. The absolute bioavailability (A.B.\%) of carvedilol was calculated by $A \cup C_{\text {oral }} / A \cup C_{\text {iv }} \times$ Dose $_{\text {i.v. }} /$ Dose $_{\text {oral }} \times 100$, and the relative bioavailability (R.B.\%) of carvedilol was estimated by $A_{U} C_{\text {with }}$ ticlopidine $/ \mathrm{AUC}_{\text {control }} \times 100$.

\section{Statistical analysis}

All mean values are presented with their standard deviation (Mean \pm S.D.). Statistical analysis was conducted using one-way ANOVA followed by a posteriori testing with Dunnett's correction. Differences were considered significant at a level of $p<0.05$

\section{RESULTS}

\section{Inhibition of CYP2C9}

The inhibitory effect of ticlopidine on CYP2C9 activity is shown in Fig. 1. Ticlopidine inhibited CYP2C9 activity in a concentration-dependent manner, and the $50 \%$ inhibition concentration $\left(\mathrm{IC}_{50}\right)$ values of ticlopidine on CYP2C9 activity was $25.2 \mu \mathrm{M}$.

\section{Rhodamine-123 retention assay}

As shown in Fig. 2, accumulation of rhodamine-123, a 


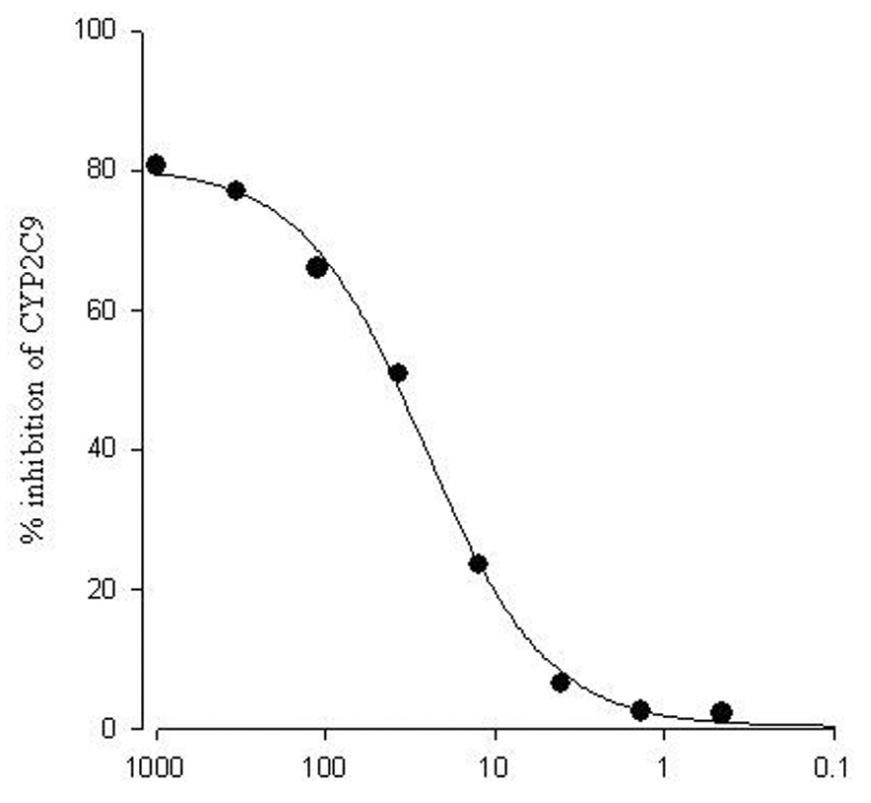

Log concentration of ticlopidine $(\mu M)$

Fig. 1. Inhibitory effects of ticlopidine on CYP2C9 activity. All experiments were performed in duplicate, and results are expressed as the percent of inhibition.

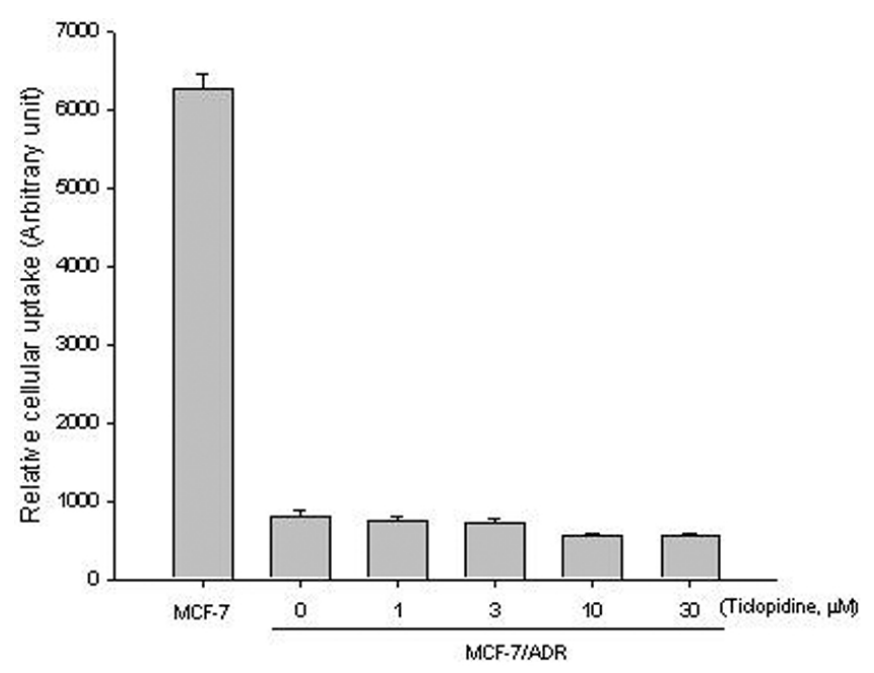

Fig. 2. Effect of ticlopidine on the cellular accumulation of rhodamine-123 in MCF-7 and MCF-7/ADR cells. Data represents mean $\pm S D$ of 6 separate samples (significant versus control MCF-7 cells).

P-gp substrate, was not raised in MCF-7/ADR cells overexpressing P-gp compared to that in MCF-7 cells lacking P-gp. The concurrent use of ticlopidine did not enhance the cellular uptake of rhodamine 123 in a concentrationdependent manner ranging from $3-30 \mu \mathrm{M}$. This result suggests that ticlopidine could not inhibit P-gp activity.

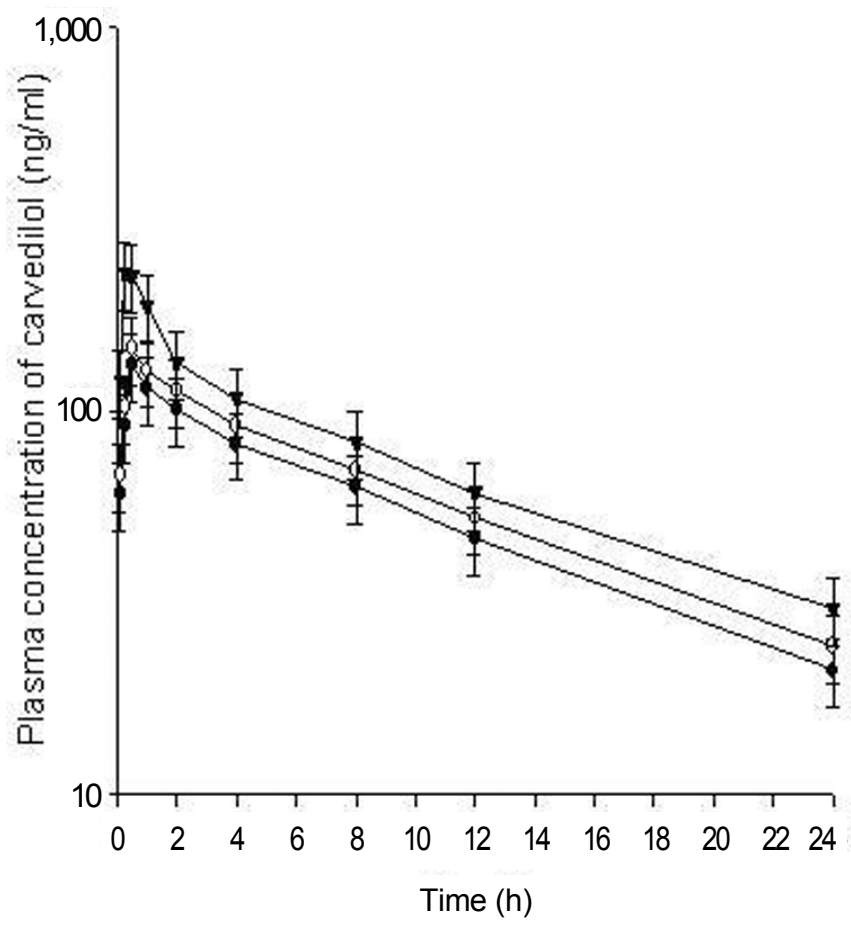

Fig. 3. Mean plasma concentration-time profiles of carvedilol after oral administration of carvedilol $(3 \mathrm{mg} / \mathrm{kg}$ ) without $(\mathbf{O})$ or with $4 \mathrm{mg} / \mathrm{kg}(\bigcirc)$ and $12 \mathrm{mg} / \mathrm{kg}(\boldsymbol{\nabla})$ of ticlopidine to rats. Bars represent the standard deviation $(n=6)$.

Table I. Mean ( \pm S.D.) pharmacokinetic parameters of carvedilol after oral administration of carvedilol $(3 \mathrm{mg} / \mathrm{kg})$ in the presence or absence of ticlopidine to rats

\begin{tabular}{lccc}
\hline \multirow{2}{*}{ Parameters } & \multirow{2}{*}{ Control } & \multicolumn{2}{c}{ Carvedilol + ticlopidine } \\
\cline { 3 - 4 } & & $4 \mathrm{mg} / \mathrm{kg}$ & $12 \mathrm{mg} / \mathrm{kg}$ \\
\hline $\mathrm{AUC}(\mathrm{ng} \cdot \mathrm{h} / \mathrm{ml})$ & $1,592 \pm 286$ & $1,812 \pm 344$ & $2,253 \pm 428^{\mathrm{a}}$ \\
$\mathrm{C}_{\max }(\mathrm{ng} / \mathrm{ml})$ & $131 \pm 23$ & $145 \pm 27$ & $227 \pm 43^{\mathrm{a}}$ \\
$\mathrm{T}_{\max }(\mathrm{h})$ & $0.5 \pm 0.087$ & $0.5 \pm 0.091$ & $0.25 \pm 0.084^{\mathrm{a}}$ \\
$\mathrm{t}_{1 / 2}(\mathrm{~h})$ & $10.2 \pm 1.8$ & $10.5 \pm 1.9$ & $11.1 \pm 2.2$ \\
A.B. $(\%)$ & $27.2 \pm 3.96$ & $36.2 \pm 4.01$ & $38.5 \pm 4.56^{\mathrm{a}}$ \\
R.B. $(\%)$ & 100 & 114 & 141 \\
\hline
\end{tabular}

Mean \pm S.D. $(n=6) .{ }^{a} p<0.05$, significant difference compared to the control. AUC: area under the plasma concentration-time curve from $0 \mathrm{~h}$ to infinity, $\mathrm{C}_{\max }$ : peak plasma concentration, $\mathrm{T}_{\max }$ : time to reach peak concentration, $t_{1 / 2}$ : half-life, A.B. (\%): absolute bioavailability, R.B. (\%): relative bioavailability compared to the control group.

\section{Effects of ticlopidine on plasma concentrations after oral administration}

The mean plasma concentration-time profiles of oral carvedilol in the presence or absence of ticlopidine are illustrated in Fig. 3. The mean pharmacokinetic parameters of carvedilol are also summarized in Table I. Fig. 3 shows the plasma concentration-time profiles of carvedilol after oral administration of $3 \mathrm{mg} / \mathrm{kg}$ of carvedilol in rats without 


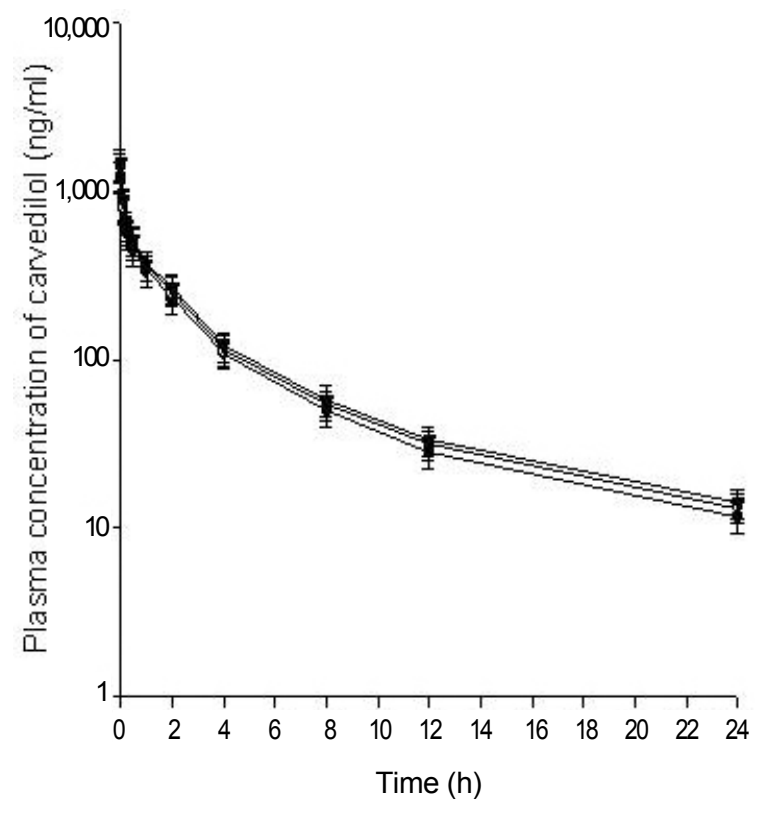

Fig. 4. Mean plasma concentration-time profiles of carvedilol after i.v. administration of carvedilol $(1 \mathrm{mg} / \mathrm{kg}$ ) without $(0)$ or with $4 \mathrm{mg} / \mathrm{kg}(\bigcirc)$ and $12 \mathrm{mg} / \mathrm{kg}(\boldsymbol{\nabla})$ of ticlopidine to rats. Bars represent the standard deviation $(n=5)$.

or with ticlopidine ( 4 or $12 \mathrm{mg} / \mathrm{kg}$ ), and the pharmacokinetic parameters of oral carvedilol are summarized in Table I. The area under the plasma concentration-time curve (AUC) was significantly $(12 \mathrm{mg} / \mathrm{kg}, p<0.05)$ increased by $14-41 \%$, and the peak concentration $\left(C_{\max }\right)$ was significantly $(12 \mathrm{mg} / \mathrm{kg}, p<0.05)$ increased by $10.7-$ $73.3 \%$ in the presence of ticlopidine after oral administration of carvedilol. Consequently, the relative bioavailability (R.B.) of carvedilol was increased by 1.14- to 1.41fold, and the absolute bioavailability (A.B.) of carvedilol in the presence of myricetin was increased by $36.2-38.5 \%$. $\mathrm{T}_{\max }$ was significantly $(12 \mathrm{mg} / \mathrm{kg}, p<0.05)$ decreased. However, there were no significant changes in the half-life $\left(t_{1 / 2}\right)$ of carvedilol in the presence of ticlopidine.

\section{Effects of ticlopidine on plasma concentrations after i.v. administration}

The mean plasma concentration-time profiles of i.v. carvedilol in the presence or absence of ticlopidine are illustrated in Fig. 4. The mean pharmacokinetic parameters of carvedilol are also summarized in Table II. Fig. 4 shows the plasma concentration-time profiles of carvedilol after i.v. $(1 \mathrm{mg} / \mathrm{kg})$ administration without or with of ticlopidine (4 or $12 \mathrm{mg} / \mathrm{kg}$ ) to rats. As shown in Table II, ticlopidine did not significantly change the pharmacokinetic parameters of i.v. administration of carvedilol, suggesting that ticlopidine may improve the oral bioavailability of carvedilol by
Table II. Mean ( \pm S.D.) pharmacokinetic parameters of carvedilol after intravenous administration of carvedilol $(1 \mathrm{mg} / \mathrm{kg})$ in the presence or absence of ticlopidine to rats

\begin{tabular}{lccc}
\hline \multirow{2}{*}{ Parameters } & \multirow{2}{*}{ Control } & \multicolumn{2}{c}{ Carvedilol + ticlopidine } \\
\cline { 3 - 4 } & & $4 \mathrm{mg} / \mathrm{kg}$ & $12 \mathrm{mg} / \mathrm{kg}$ \\
\hline $\mathrm{AUC}(\mathrm{ng} \cdot \mathrm{h} / \mathrm{ml})$ & $1,949 \pm 369$ & $2,118 \pm 389$ & $2,219 \pm 421$ \\
$\mathrm{CL}_{\mathrm{t}}(\mathrm{ml} / \mathrm{min} / \mathrm{kg})$ & $850 \pm 171$ & $787 \pm 157$ & $752 \pm 150$ \\
$\mathrm{t}_{1 / 2}(\mathrm{~h})$ & $8.0 \pm 1.5$ & $8.2 \pm 1.7$ & $8.3 \pm 1.8$ \\
$\mathrm{R} . \mathrm{B} .(\%)$ & 100 & 109 & 114
\end{tabular}

Mean \pm S.D. $(n=5)$. AUC: area under the plasma concentrationtime curve from time 0 to infinity, $\mathrm{CL}_{\mathrm{t}}$ : total body clearance, $\mathrm{t}_{1 / 2}$ : terminal half-life, R.B. (\%): relative bioavailability compared to the control group.

more increasing the absorption or reducing gut wall metabolism than renal elimination.

\section{DISCUSSION}

CYPs enzymes contribute significantly to the first-pass metabolism and oral bioavailability of many drugs. The first-pass metabolism of compounds in the intestine limits absorption of toxic xenobiotics and may ameliorate adverse effects. Moreover, inhibition or induction of intestinal CYPs may be responsible for significant drug and drug interactions when one agent decreases or increases the bioavailability and absorption rat constant of a concurrently administered drug (Kaminsky and Fasco, 1991).

Therefore, inhibitors against both CYP2C9 and P-gp should have a great impact on the bioavailability of many drugs where CYP2C9 metabolism as well as P-gp mediated efflux is the major barrier to the systemic availability.

The inhibitory effect of ticlopidine against CYP2C9mediated metabolism was confirmed by the employment of recombinant CYP2C9 enzyme. As shown in Fig. 1, ticlopidine exhibited inhibitory effect against CYP2C9-mediated metabolism with $\mathrm{IC}_{50}$ of $25.2 \mu \mathrm{M}$. The ticlopidine presents less inhibition of CYP2C9 compared to that of ketoconazole with $\mathrm{IC}_{50}$ of $6 \mu \mathrm{M}$ (McGinnity et al., 2005). However, inhibitory effect aganst CYP2C9 of ticlopidine is more potent than that of piroxicam with $\mathrm{IC}_{50}$ of $32 \mu \mathrm{M}$ or sertraline $\mathrm{IC}_{50}$ of $48 \mu \mathrm{M}$ (McGinnity et al., 2005). Furthermore, the cell-based assay using rhodamine-123 indicated that ticlopidine $(30 \mu \mathrm{M})$ could not significantly inhibit P-gp-mediated drug efflux (Fig. 2). Therefore, the pharmacokinetic characteristics of carvedilol were evaluated in the absence and presence of ticlopidine in rats. Human CYP2C9 and 3A4 and rat $\mathrm{CYP} 2 \mathrm{C} 11$ and $3 \mathrm{~A} 1$ have 77 and $73 \%$ protein homology, respectively (Lewis, 1996). Rats were selected as an animal model in this study to evaluate the potential pharmacokinetic interactions mediated by $\mathrm{CYP} 2 \mathrm{C}$, al- 
though there may be some difference in enzyme activity between rat and human (Cao et al., 2006). Therefore, ticlopidine might possible increase absorption of carvedilol in the intestine through the inhibition of CYP2C9.

In addition to its extensive metabolism by CYP2C9, carvedilol appeared to be the substrate of $\mathrm{P}$-gp, suggesting that P-gp and CYP2C9 should act synergistically to limit the oral bioavailability of carvedilol (Saeki et al., 1993). Therefore, we investigated the cell-based P-gp activity using rhodamne-123 and the result showed that ticlopidine did not affect P-gp activity. Studies on drug interactions with grapefruit juice have provided much understanding of the role of intestinal CYP450 in the absorption of orally administered drugs. CYP2C9 is the predominant P450 present in the small intestine (Kolars et al., 1992). Orally administered carvedilol is a substrate for CYP2C9-mediated metabolism and P-gp-mediated efflux. Ticlopidine did not significantly change the pharmacokinetic parameters of i.v. administration of carvedilol, suggesting that ticlopidine may improve the oral bioavailability of carvedilol by more increasing the absorption or reducing gut wall metabolism via inhibition of CYP2C9-mediated metabolism of carvedilol than P-gp-mediated efflux and renal elimination.

The increased bioavailability of carvedilol might be mainly due to inhibition CYP2C9-mediated metabolism rather than P-gp-mediated efflux of carvedilol in the intestine and/or liver and renal eliminatin by ticlopidine. Therefore, concomitant use of ticlopidine with carvedilol will require close monitoring for potential drug interactions.

\section{REFERENCES}

Bart, J., Dijkers, E. C., Wegman, T. D., de Vries, E. G., van der Graaf, W. T., Groen, H. J., Vaalburg, W., Willemsen, A. T. and Hendrikse, N. H. (2005). New positron emission tomography tracer [(11)C]carvedilol reveals P-glycoprotein modulation kinetics. Br. J. Pharmacol. 145, 1045-1051.

Bristow, M. R., Gilbert, E. M., Abraham, W. T., Adams, K. F., Fowler, M. B., Hershberger, R. E., Kubo, S. H., Narahara, K. A., Ingersoll, H., Krueger, S., Young, S. and Shusterman, N. (1996). Carvedilol produces dose-related improvements in left ventricular function and survival in subjects with chronic heart failure. MOCHA Investigators. Circulation 94, 28072816.

Bristow, M. R., Larrabee, P., Minobe, W., Roden, R., Skerl, L., Klein, J., Handwerger, D. and Port, J. D., Müller-Beckmann B. (1992). Receptor pharmacology of carvedilol in the human heart. J. Cardiovasc. Pharmacol. 19, S68-80.

Buur, T., Larsson, R., Berglund, U., Donat, F. D. V. M. and Tronquet, C. (1997). Pharmocokinetics and effect of ticlopidine on platelet aggregation in subjects with normal and impaired renal function. J. Clin. Pharmacol. 37, 108-115.

Cao, X, Gibbs, S. T., Fang, L., Miller, H. A., Landowski, C. P, Shin, H. C., Lennernas, H., Zhong, Y., Amidon, G. L., Yu, L.
X. and Sun, D. (2006). Why is it challenging to predict intestinal drug absorption and oral bioavailability in human using rat model. Pharm. Res. 23, 1675-1686.

Cleland, J. G., Bristow, M. R., Erdmann, E., Remme, W. J., Swedberg, K. and Waagstein, F. (1996). Beta-blocking agents in heart failure. Should they be used and how? Eur. Heart J. 17, 1629-1639.

Cournot, A., Lim, C., Duchier, J. and Safar, M. (1992). Hemodynamic effects of carvedilol after acute oral administration in hypertensive and normal subjects. J. Cardiovasc. Pharmacol. 19, S35-39.

Crespi, C. L., Miller, V. P., Penman, B. W. (1997). Microtiter plate assays for inhibition of human, drug-metabolizing cytochromes P450. Anal. Biochem. 248, 188-190.

DasGupta, P., Broadhurst, P. and Lahiri, A. (1991). The effects of intravenous carvedilol, a new multiple action vasodilatory beta-blocker, in congestive heart failure. J. Cardiovasc. Pharmacol. 18, S12-16.

Feuerstein, G. Z., Bril, A. and Ruffolo, R. R. Jr. (1997). Protective effects of carvedilol in the myocardium. Am. J. Cardiol. 80, 41L-45L.

Gent, M., Blakely, J. A., Easton, J. D., Ellis, D. J., Hachinski, V. C., Harbison, J. W., Panak, E., Roberts, R. S., Sicurella, J. and Turpie, A. G. (1989). The Canadian American ticlopidine study (CATS) in thromboembolic stroke. Lancet. 1, 1215-1220.

Gidal, B. E., Sorkness, C. A., McGill, K. A., Larson, R. and Levine, R. R. (1995). Evaluation of a potential enantioselective interaction between ticlopidine and warfarin in chronically anticoagulated patients. Ther. Drug Monit. 17, 33-38.

Hampton, J. R. (1996). Beta-blockers in heart failure--the evidence from clinical trials. Eur. Heart J. 17, 17-20.

Hass, W. K., Easton, J. D., Adams, H. P. Jr., Pryse-Phillips, W., Molony, B. A., Anderson, S. and Kamm, B. (1989). A randomized trial comparing ticlopidine hydrochloride with aspirin for the prevention of stroke in high-risk patients. N. Engl. J. Med. 321, 501-507.

Haynes, R. B., Sandler, R. S., Larson, E. B., Pater, J. L. and Yatsu, F. M. (1998). A critical appraisal of ticlopidine, a new antiplatelet agent. Effectiveness and clinical indications for prophylaxis of atherosclerotic events. Arch. Intern. Med. 152, 1376-1380.

Ito, M. K., Smith, A. R. and Lee, M. L. (1992). Ticlopidine: a new platelet aggregation inhibitors. Clin. Pharm. 11, 603-617.

Janzon, L., Bergqvist, D., Boberg, J., Boberg, M., Eriksson, I., Lindgärde, F., Persson, G., Almgren, B., Fagher, B. and Kjellström, T., et al. (1990). Prevention of myocardial infarction and stroke in patients with intermittent claudication; effects of ticlopidine. Results from STIMS, the Swedish Ticlopidine Multicentre Study. J. Intern. Med. 227, 301-308.

Kaminsky, L. S. and Fasco M. J. (1991). Small intestinal cytochromes P450. Crit. Rev. Toxicol. 21, 407-422.

Ko, J. W., Desta, Z., Soukhova, N. V., Tracy, T. and Flockhart, D. A. (2000). In vitro inhibition of the cytochrome P450 (CYP450) system by the antiplatelet drug ticlopidine: potent effect on CYP2C9 and CYP2D6. Br. J. Clin. Pharmacol. 49, 343-351.

Kolars, J. C., Schmiedlin-Ren, P., Schuetz, J. D., Fang, C. and Watkins, P. B. (1992). Identification of rifampin-inducible P450IIIA4 (CYP2C9) in human small bowel enterocytes. $J$. Clin. Invest. 90, 1871-1878. 
Lewis, D. F. V. (1996). Cytochrome P450. Substrate specificity and metabolism. In Cytochromes P450. Structure, Function, and Mechanism, pp. 122-123. Taylor \& Francis, Bristol.

Lund-Johansen, P., Omvik, P., Nordrehaug, J. E. and White, W. (1992). Carvedilol in hypertension: effects on hemodynamics and 24-hour blood pressure. J. Cardiovasc. Pharmacol. 19, S27-34.

McGinnity, D., Tucker, J., Trigg, S. and Riley, R. (2005). Prediction of CYP2C9-mediated drug-drug interactions: a comparison using data from recombinant enzymes and human hepatocytes. Drug Metab. Dispos. 33, 1700-1707.

McTavish, D., Campoli-Richards, D. and Sorkin, E. M. (1993). Carvedilol. A review of its pharmacodynamic and pharmacokinetic properties, and therapeutic efficacy. Drugs 45, 232258.

Morgan, T. (1994). Clinical pharmacokinetics and pharmacodynamics of carvedilol. Clin. Pharmacokinet. 26, 335-346.

Neugebauer, G., Akpan, W., von Mollendorff, E., Neubert, P. and Reiff, K. (1987). Pharmacokinetics and disposition of carvedilol in humans. J. Cardiovasc. Pharmacol. 11, S85-88.

Neugebauer, G. and Neubert, P. (1991). Metabolism of carvedilol in man. Eur. J. Drug Metab. Pharmacokinet. 16, 257-260.

Oldham, H. G. and Clarke, S. E. (1997). In vitro identification of the human cytochrome P450 enzymes involved in the metabolism of $\mathrm{R}(+)$ - and S(-)-carvedilol. Drug Metab. Dispos. 25, 970-977.

Saeki, T., Ueda, K., Tanigawara, Y., Hori, R. and Komano, T. (1993). P-glycoprotein-mediated transcellular transport of MDR-reversing agents. FEBS. Lett. 324, 99-102.

Saltiel, E. and Ward, A. (1987). Ticlopidine. A review of its pharmacodynamic and pharmacokinetic properties, and therapeutics efficacy in platelet-dependent disease states. Drugs 34, 222-262.

Shah, J., Fratis, A., Ellis, D., Murakami, S. and Teitelbaum, P. (1990). Effect of food and antacid on absorption of orally administered ticlopidine hydrochloride. J. Clin. Pharmacol. 30, 733-736.

Solomon, D. H. and Hart, R. G. (1994). Antithrombotic therapies for stroke prevention. Curr. Opin. Neurol. 7, 48-53.

Verhaeghe, R. (1991). Prophylactic antiplatelet therapy in peripheral arterial disease. Drugs 42, 51-57.

Zarghi, A., Foroutan, S. M., Shafaati, A. and Khoddam, A (2007). Quantification of carvedilol in human plasma by liquid chromatography using fluorescence detection: application in pharmacokinetic studies. J. Pharm. Biomed. Anal. 44, 250253. 